\title{
Women's participation in decentralized local governance: the case of pastoral and non-pastoral women in Kondoa local authority, Tanzania'
}

\author{
Haidari Pascal Misafi \\ Department of Conflict and Development Studies, Ghent University
}

\begin{abstract}
This summary of my PhD thesis explains the reasons behind and the effects of pastoral and nonpastoral women's participation in decentralized local governance in Tanzania. A body of knowledge exists on participation and gender in Tanzania. However, beyond plain statistics, there is limited information on women's experiences in participation within decentralized local governance in the country. Two main theoretical streams exist in literature concerning participation and gender. One stream of literature argues that women's descriptive participation leads to substantive women's participation. The other stream argues that it is important to focus on what specific actors do to represent women's concerns and not solely on women's descriptive participation. The data analysed in this report were collected in Kondoa Local Authority, Tanzania. Within Kondoa, the two dominant women groups -pastoral women and non-pastoral women- were selected as case studies. Based on observations, interviews and focus group discussions, I have found that despite the presence of pastoral and non-pastoral women in governance, the quality of women participation is low. Both case studies reveal that women's participation is mainly limited to their physical presence or the nominal level. Similarly, I have shown that the dynamics of women's participation determine women's descriptive and substantive participation in governance. Additionally, I have found that incentives, access to information and power relations significantly determine women's presence in and contributions to governance. Moreover, women's interest in local governance and their knowledge of the Kiswahili language are also determining factors behind their substantial participation in decision-making. Furthermore, I have found that women in governance have no impact on policy changes concerning women. A general conclusion in this report is that there is a mismatch between women in governance and participation. I argue that having women in governance does not guarantee participation. These results challenge both the women's descriptive representation and women's substantive representation theoretical perspectives. I therefore recommend that: (I) policies regarding women's participation should be reconstructed to ensure not only an increase in women in governance but also that women in that position are able to act for women; (2) a holistic approach
\end{abstract}


is required to understand underlying forces that determine the level and quality of women's participation in governance; (3) interventions for enhancing women's participation in governance should take into consideration unique dichotomies and peculiarities among women.

Key words: participation, pastoral women, non-pastoral women, decentralized local governance

\section{Introduction}

The present research explains women's participation in decentralized local governance in Tanzania. It specifically explores how and why, and the effects of pastoral and non-pastoral women's participation in decentralized local governance in Tanzania. The research stems from the understanding that the issue of women's participation in governance in Tanzania has become increasingly prominent in the area of governance. The centrality of women in the governance agenda is predicated on the fact that although women constitute slightly more than half of the country's population, they are disproportionately represented in the governance realm. Cognizant of this fact, the government of Tanzania has launched measures to increase the number of women representatives in decision-making organs, with the hope that women's issues will be equally promoted in such organs.

The government's major effort to enhance women's numbers in decision-making bodies was the 1992 constitutional reform that, among other things, introduced gender quotas in parliament and local councils. The gender quotas increased the proportion of women representatives in local councils from $15 \%$ to $25 \%$ (URT, 2008). Further increases in the number of women representatives were recorded in the year 2000 when the government made the I 3 th constitutional amendment to enhance women's political empowerment in line with the Beijing Declaration of 1995 and the SADCC declaration of I997 (Meena, 2003; 2009). This resulted in an increase in the percentage of women representatives in local councils from $25 \%$ to $33.3 \%$ (URT, 2009). Currently, Tanzania is in the process of writing a new constitution and the draft constitution recommends a 50/50 representation among males and females in parliament and local government decisionmaking organs. Previous to this, in I998, the government adopted the Local Government Reform programme which aimed at decentralizing governance so as to enhance people's participation in decision-making.

Tanzania has so far made significant progress in terms of the numbers of women who participate in governance. However, the question remains whether numbers alone necessarily translate into participation. As we embark on this research project, there is little information on women's experiences in participation beyond bare statistics. It is against this backdrop that we explored information on women's experiences in participation in governance in Tanzania. Specifically we explored how pastoral and non-pastoral women participate in governance. This provided insight into women's participation beyond the numerical dimension. Additionally, we looked at the different dynamics of pastoral and non-pastoral women's participation and their effects. Understanding the different dynamics of women's participation in governance enabled us to uncover a broad picture of underlying forces that explain the ways in which pastoral and non-pastoral 
women participate in governance. Understanding the effects of women's participation in governance enables us to gauge whether numerical change in itself brings about substantive changes in the setting of agendas, changes in priorities, decisions on different domains and changes in service delivery.

The data analysed in this research were collected in Kondoa, one of the five districts of the Dodoma Region of Tanzania. ${ }^{2}$ The district has been randomly selected from the first 38 districts which started to implement the Local Government Reform Programme. The reform aimed at decentralizing governance in order to enhance citizen's participation in decision-making (Chaliga, 2008; URT, 2008). Within Kondoa, the two dominant women groups - pastoral women and non-pastoral women - were selected as case studies. In this study I employed qualitative research methods. In this regard, I used interviews, participant observations and focus group discussions to gather information for the study. The study randomly selected two wards namely Gwandi and Mrijo from 35 wards composing Kondoa Local Authority. From the wards, four villages were randomly selected, two villages from each ward. The villages selected were Gwandi and Rofati from Gwandi ward, while Magasa and Olboloti represented Mrijo ward. In each village Io respondents were randomly selected. The study also garnered information from the chairpersons and executives of the four selected villages who were purposely selected. In addition, the District Chairperson and District Executive Director, the two constituent Members of Parliament in the district, were also included in the sample. Moreover, the sample size consisted of the two women Ward Councilors (from Gwandi and Mrijo wards) nominated under special seat to represent women in the District Council. This makes a total sample size of this study to be $52.3^{3}$ To analytically link theoretical perspectives and the collected data, I employed the critical mass and critical actors theoretical perspectives, women descriptive representation, women substantive representation, women in development as well as gender and development approaches. The following are results that are summarized and presented based on the key research questions.

\section{Pastoral and non-pastoral women participation in a decentralized local governance}

As I indicated previously in this document, one of the key research questions for this study was, how do pastoral and non-pastoral women participate in decentralized local governance in Tanzania? I found that pastoral women and non-pastoral women's participation in governance was mainly descriptive. Data indicate that, on the one hand, pastoral women have limited freedom to participate in voting, as they first have to seek

Unlike most of the countries in Africa, Tanzania has been experiencing a steady increase in the number of women in decision-making organs over the past ten years. Pastoralism is one of the dominant livelihood system in Tanzania (Kipuri and Ridgewell, 2008).

3 The selection of sample size is based on literature which suggests that there is no hard rule in the selection of sample size for qualitative researches. "A small sample size is useful in qualitative studies as it allows a researcher to spend a lot of time on a respondent and obtain in depth information from him or her as opposed to quantitative studies that require large sample size and less detailed information from respondents" (Walliman, 2006). 
permission from their spouses or male elders before they can take part in governance matters. On the other hand, when pastoral men give women permission to participate in voting activities, they make sure they can control the vote of the women. This suggests that men control women's participation in governance. Women participate under men's influence, thus confirming the main weakness of this kind of participation, overlooking men's responsibility.

That notwithstanding, I found that unlike their male counterparts the majority of pastoral women did not participate in vying for leadership positions. A few pastoral women did attempt to participate in vying for leadership positions, however they did not succeed as they faced several restrictions from pastoral men. These findings confirm the gender and development approach supported by Ostergaard (1992) and Pajvančić-Cizelj, (20II). Similarly, I found that during campaign meetings pastoral women participated as listeners to the campaigners without questioning campaign candidates. I also observed the same during general public meetings as well as in decision-making organs such as Village Assemblies. Women attended meetings but did not speak or contribute in it either. This challenges the critical mass argument that link women's statistics to participation. During the fieldwork, I further observed that pastoral women did not attend public debates or protests. This implies that pastoral women have limited capacity to convey their demands to the government. Responses from the non-pastoral women case study indicate that non-pastoral women voted with limited information about candidates they voted for. Others voted without considering gender as an important aspect in governance. Few women attempted to vie for leadership positions, and the majority of those who did focused on the seats reserved for women which were less competitive than constituency seats. The few women representatives who in most cases adopted background positions during meetings defended their positions rather than women's interests. Such findings not only challenge the idea of gender quota but also contradicts the whole idea of women's descriptive participation.

Additionally, during fieldwork time, I observed that non-pastoral women attended meetings and campaigns without having enough information about the meeting/campaigns prior to attendance, while others were persuaded by their spouses to vote. These findings, on the one hand, confirm the argument that in decentralized local governance, women get opportunities to participate descriptively. On the other hand, these findings confirm the arguments that there are politics of participation within decentralized local governance.

During the same fieldwork, I found that non-pastoral women consider participation in public protest as unethical and so something they would not consider doing. Likewise, I found that non-pastoral women were sometimes involved in debates about general issues including gossip that were not related to governance issues. This entails that sometimes problems of women's participation come from women themselves. In this regard, the suggestion provided by the women in the development approach requires special treatment in order to bring about gender equality. 
As a whole, the general view of how pastoral and non-pastoral women participate in decentralized local governance is mainly descriptive with limited evidence of women acting for women. I therefore argue that women in governance does not necessarily translate into women's ability to influence decision-making. Women's participation is monitored and controlled by men which affects the outcome of women's participation in governance.

\section{Dynamics of pastoral and non-pastoral women's participation in decentralized local governance}

The second research question that guided my study looked for the reasons why pastoral and non-pastoral women participate in the way they do. Through this question I obtained data on the different dynamics of pastoral and non-pastoral women's participation in local governance. From the data I presented and discussed in chapter four, women's dynamics of participation take a number of different forms.

First, I found that there were enabling opportunities for women's participation in decision-making such as the affirmative action policy that created special seats for women to participate in decision-making organs. This was taken to be an advantage especially for non-pastoral women as it enabled them to acquire all the reserved seats in Gwandi and Mrijo wards as well as in village councils in the wards. In addition, the government, through its decentralisation policy that devolved decision-making power to the lowest level of governance, made it easier for women to participate in meetings, at least numerically, due to proximity. These opportunities at least ensured the presence of women in governance.

Second, I found that social and cultural norms, power relations, gender stereotypes, incentives and individual factors determined women's presence and acts in governance. For instance, while norms and values restricted women from participating in public activities, they also defined how women should participate in governance. It is social norms that define rights and responsibilities as well as appropriate behavior and expectations for women and men, which in most cases disadvantage women. Apart from social norms, I also found power relations between men and women determined women's presence as well as their role in governance. Men made strategic decisions not only for women to get involved in governance, but also for their roles in governance. Observations made by Schanke and Lange (2008) that Tanzania is dominated by strong patriarchal systems proved to be true throughout this research. Therefore I agree with Gaventa's theoretical understanding that existing power relations between men and women determine women's presence and ability to influence decision-making (Gaventa, I980). In addition, I found that gender stereotypes also determine women's presence and their ability to act for women in general. For instance, I found that both men and women believe that women are the weaker sex, that women, unlike men, do not have the ability to participate in certain public activities. This validates Meena's observation that despite being involved in the struggle for independence in Tanzania, women were not nominated to become ministers in the first cabinet after independence, on the chauvinistic grounds that they 
were incapable of becoming cabinet ministers (Meena, 2009). Moreover, in my results I indicated that, on the one hand, incentives provided a motive or constraint for women's participation, while on the other hand, incentives influenced women's contribution in meetings. This is congruent with Holvoet and Inberg's perspective through which it is seen that individuals become politically active because of various incentives they get or anticipate receiving (Holvoet and Inberg, 20II). The results also confirm Meena's observation that incentives are a key determining factor for most women vying for leadership positions in Tanzania. Nonetheless, I indicated in this study that individual women's interests as well as access to information were also linked to determining women's activities and the number of women taking part in decision-making. For instance, I noted that some women voted for CCM, the ruling party, because of their interest in the party or in a particular candidate of CCM. Others did not attend various public meetings because they did not receive calls for the meetings. Similarly, I found that most women participated in electoral processes, campaigns and voting because of various sensitizations. These results confirm the literature which considers that participation is a voluntary act that can determine women's roles in politics as well as their social actions especially when they have access to information.

Related to interests and access to information, I found that knowledge of the Kiswahili language also contributed to determining women's participation in governance, both descriptively and substantively. This was particularly evident among pastoral women who indicated that they failed to participate in most public activities due to the language barrier. Moreover, I observed that the Kiswahili language knowledge influenced non-pastoral women's ability to make contributions in meetings. The non-pastoral women's language skills meant a greater ease of representation of their concerns in public forums. Similarly, the pastoral women's language barrier confirms the limited articulation of women's interests.

As stated in the theoretical literature, in general, the dynamics of women's participation is linked to either women's presence and roles in governance. This study indicates indeed that the dynamics of women's participation are linked to both women's presence and women's deeds in governance. Nevertheless, analysis of the results indicates that the dynamics of women's participation exist in a complex synergy mode and their efficacy varies between pastoral and non-pastoral women's groups. Therefore, I claim that studying dynamics of pastoral and non-pastoral women's participation is a complex issue that cannot be understood by studying either the presence of women or women's deeds in governance alone.

\section{Effects of pastoral and non-pastoral women's participation in decentralized local governance}

My main aim in this section was to explore information that will provide answers to the third research question: what are the effects of pastoral and non-pastoral women's participation on decentralized local governance? As shown in the introduction of this paper, my main focus in this particular research looks at women's participation effects 
in the agenda setting, change in priorities, decisions on different domains, and different outcomes in services delivery. The findings indicate that pastoral and non-pastoral women's participation has no effect on governance. The findings point out that women have limited participation in agenda setting even when they had the opportunity to do so. As a result, men dominate agenda setting. Most of the agendas were pro men with only a limited number of topics raising women's concerns. The results do not correspond with Pitkin's acceptance that women in governance often leads to changes in political discourse(s) (Pitkin,I967). Furthermore, the results revealed that there was no change in priorities as women's priorities were not put forward by women themselves and were not considered as urgent as other matters. Consequently, only general priorities set by the government and those supported by men prevailed in decision-making organs. This rejects Child and Krook's thesis on women's presence in governance being perceived as bringing positive impact in the representation of women's issues (Child and Krook, 2008). Likewise, I found that there is limited effect in decisions on different domains despite women's participation. For instance, despite the numbers of women in decisionmaking organs as well as several challenges facing women, they had no voice to influence decisions in different domains. These results contradict a large body of literature that shows women represent women, therefore, increasing the number of women in governance policy to have an impact on women's interests and gender equality (Phillips, I995; Yoon, 20II; Fopahunda, 20I2).

In yet another perspective, I have indicated in this research the outcome was limited in terms of the category service delivery realized as a consequence of women's participation in governance. The women have continued facing similar challenges regarding limited service delivery for years, irrespective of their participation in campaigns, attendance to meetings, voting and having women representatives in decision-making organs. Similarly, results indicate that pastoral women have been facing problems of limited access to health care services, water and medicine for their livestock, and thus are required to travel long distances to get access to the needed services. Moreover, both pastoral and non-pastoral women face serious shortages in maternal health services in the study areas; but the women did not take initiatives to address these issues as problems that require their attention. This implies that there is a mismatch between women's participation in governance and defending their concerns. In this vein, I concur with the arguments by Krook and Childs (2009) that the effects of women's participation should not be gauged from their mere involvement in governance, but by the role played by actors in defending women's concerns.

In this regard, I conclude that despite women's participation in decentralized local governance, there has been limited effect in terms of agenda setting, bringing changes in priorities, decision in different domains as well as changes in service delivery. The effects of women's participation in governance are informed and controlled by cultural traits as well as men's dominance. I therefore argue that while theoretically the presence of women in governance brings changes to policies concerning women, this was not demonstrated by the findings of this study. I agree with the gender and development perspective that 
the effects of women's participation cannot be realized by sex representation but through addressing issues of gender relations.

\section{General conclusion}

A general conclusion in this research is that there is limited pastoral and nonpastoral women's participation in decentralized local governance beyond numbers in Tanzania. This contradicts theoretical perspectives that tie women politics to numerical representations. I argue that having women in governance does not guarantee women's participation in governance. Therefore, the discourse about participation and gender has to move beyond women's presence in governance and address the broader issues regarding the politics of women's participation in governance.

\section{Theoretical implications of the study}

This research depicted a number of findings that have implications for the existing theoretical perspectives concerning participation and gender.

First, the research contradicts the theoretical perspective that emphasizes women's descriptive participation in governance as a solution towards attainment of their substantive participation in governance. While it is theoretically assumed that women in governance guarantee their substantive participation, this research contradicts such a stand. The research shows that issues of participation and gender cannot be dealt with by women's presence alone. They are strongly connected to broader socio-cultural and economic factors underlying pastoral and non-pastoral women's participation in governance.

In addition, the research contrasts the theoretical argument that women's issues are best represented by women. The study reveals that there is no relationship between women's participation and the representation of their concerns. The analysis of results reveals that women's representatives do not in general represent women's concerns.

Second, this research consists of rigorous imperial evidence of social norms and values, gender stereotypes, power relations, incentives, interests and access to information as determining factors for pastoral and non-pastoral women's descriptive and substantive participation in governance. Moreover, the research argues that the dynamics of women's participation vary in degree of influence on pastoral and non-pastoral women's participation in governance.

Third, the research provides additional insights into the role of the Kiswahili language in determining women's participation in governance. Literature on participation and gender in Tanzania rarely provides adequate and convincing information on the role of the Kiswahili language. This research shows that the Kiswahili language determines women's descriptive and substantive participation in governance in Tanzania.

Fourth, the research contrasts the theoretical argument that critical actors influence policy changes related to women's concerns. It is established in this research that neither men nor women defended women's concerns. It was for instance noted that women supported concerns of men and the general public, but men rarely supported women's concerns. Some women believed themselves to have the ability to represent women's concerns but failed to do so because of cultural ties that constrained them from being 
critical actors. This implies that the critical actor's theoretical perspective does not hold in this research.

Fifth, most studies on participation and gender are limited to studying pastoral and non-pastoral women categories in isolation. This study is unique from a body of literature on participation and gender in Tanzania as it expounds experiences of the two women categories in participation in governance beyond numbers and their level of involvement in governance.

\section{Enhancing pastoral and non-pastoral women's participation in decentralized local governance in Tanzania.}

From pastoral and non-pastoral women's experience in participation in decentralized local governance in Tanzania the following can be learned.

First, from the observational findings we learn that neither the presence of women in governance nor their critical acts alone can guarantee substantive pastoral and nonpastoral women's participation in Tanzania. I therefore argue for a hybrid approach to enhance and guarantee women's participation in governance. The approach should look to both increasing women's numbers as well as enhancing their roles in defending women's interests in governance.

Second, there are different dynamics determining women's participation in governance. Nevertheless, understanding the dynamics of pastoral and non-pastoral women's participation is complex because the dynamics are interlinked, and one factor cannot guarantee explanation of women's participation. For instance, while norms provide for women's participation in certain activities such as meetings, they also define how the women should behave in meetings. Likewise, whereas incentives pull women to participate in meetings, incentives also control women's contributions in meetings. Similarly, whereas access to information determined women's attendance to meetings, lack of information made women fail to contribute in meetings. Therefore in my view I argue that, to guarantee women's substantive participation, a holistic approach is required to understand underlying forces determining women's participation in governance.

Third, with regard to the effects of pastoral and non-pastoral women's participation in governance, I demonstrated that there is no relationship between the presence of women in governance and the outcomes concerning women issues. In this regard, I remain convinced that the only possible way to achieve effects of women's participation in governance is by reconstructing policies governing women's participation in governance. The policies should not only focus on ensuring women in governance, but also deconstructing gender identities as well as relations between men and women that undermine women's inputs and outcomes concerning women's issues. For instance, the on-going process of writing the constitution in Tanzania should not only aim at balancing the number of men and women in decision-making organs but also guarantee representation of women's interests in the organs. 
Finally, I observed that although pastoral and non-pastoral women live in the same area, they have different experiences in terms of their participation in governance. From the study findings pastoral women experience more severe conditions for participation than non-pastoral women due to various reasons as such as the influence of social norms and gender stereotypes, access to information as well as the Kiswahili language. I therefore argue that interventions for women's participation in governance require consideration of the unique dichotomies and peculiarities among women.

\section{Suggestions for further research}

The study cannot claim to have exhausted all information regarding pastoral and non-pastoral women's experience in participation in governance. Further research needs to be done in order to better understand pastoral women and non-pastoral women's experiences in their participation in specific ethnic groups, such as pastoral Maasai versus the Warangi, a non-pastoral ethnic group. I find this is interesting because within pastoral and non-pastoral women categories there are different ethnic groups with different cultural variations. By narrowing pastoral and non-pastoral women groups into smaller groups different and detailed experiences in participation in governance among women can be described and analysed. The Maasai and Warangi as dominant ethnic groups of pastoral and non-pastoral groups respectively in Kondoa, provide for justification for choosing the women ethnic groups. Additionally, I find that there is a need for further research to study how women's participation at the local level influences or affects governance at national level. This is important as it will help to establish whether there is any policy change at national level which is due to women's participation. Moreover, it would be interesting to conduct further research on governance "inside" pastoral households in order to find out how it relates to or affects governance "outside" households. I find this is equally important because there is a link between governance in households and pastoral women's participation in governance. Understanding the link helps us to better understand and establish appropriate measures to deal with problems of women's participation in governance. Additionally, I find that there is a need to understand the relationship between women representatives and pastoral women. How often do they consult pastoral women? How often do they go back to the grassroots and meet pastoral women so as to give them feedback, hope and encouragement to participate in politics? What is pastoral women's perception of women's representatives or the government? Through my fieldwork experience in this research, I came to learn that all women representatives in decision-making organs belonged to the non-pastoral women category. Likewise, I also learned that pastoral women have different interests from non-pastoral women. Therefore, it would be interesting to know if non-pastoral women represent pastoral women's concerns. 


\section{References}

Chaligha, A. (2008). Local Autonomy and Citizen Participation in Tanzania: From a Local Government Reform perspective, Dares Salaam, Mkuki na Nyota Publishers.

Childs, S. \& Krook, M. (2009). Analysing women's substantive representation: From critical mass to critical actors. Government and Opposition, 44 (2) pp. I25-I 45.

Childs, S. and Krook, M. (2008). 'Critical mass theory and women's political representation'. Journal of Political Studies 56(3) pp. 725-736.

Fopahunda, T. (2012). Gender and Development: Challenges to Women Involvement in Nigeria's Development. International Journal of Academic Research in Business and Social Sciences, 2 (6) pp. I4-28.

Gaventa, J. (I980). Power and powerlessness: Quiescence and Rebellion in an Appalachian Valley, Oxford, Clarendon Press.

Holvoet, N. \& Inberg, L. (20II). Gender mainstreaming within the context of changing aid modalities: Evidence from Tanzania. A working paper. Institute of Development Policy and Management, Antwerp.

Kipuri, N. \& Ridgewell, A. (2008). A double Bind: The Exclusion of Pastoralist Women in the East and Horn of Africa, Minority rights group report. Retrieved on Ioth April 2010 from www.minorityrights.org.

Meena, R. (2009). Women Participation in Positions of Power and Influence in Tanzania. A Paper presented during the 2009 REDET Conference, Dares Salaam.

Meena, R. (2003). The Politics of Quotas in Tanzania. A Paper presented at the International Institute for Democracy and Electoral Assistance (IDEA)/Electoral Institute of Southern Africa (EISA)/ Southern African Development Community (SADC) Parliamentary Forum Conference, Pretoria.

Ostergaard, L. (1992). Gender and Development. A Practical Guide. London: Routledge.

Pajvančić-Cizelj, A. (20II). Gender and Development. Temida, I4 (I) pp. 67-82.

Phillips, A. (1995). The politics of presence. Oxford. Clarendon Press.

Pitkin, H. (1967). The Concept of Representation. Berkeley, Los Angeles: University of California Press.

Schanke, L. \& Lange, S.(2008). Decentralisation and Gender: Coordination and Cooperation on Maternal Health Issues in Selected District Councils in Tanzania. Chr Michelsen Institute report. Retrieved on roth June 2013 from www.cmi.no/publications.

URT. (2008). The State of Decentralisation and Local Governance, Dares Salaam.

URT. (2009). Progress Towards Good Governance and Increased Accountability, Dares Salaam.

Walliman, N. (2006). Social Research Methods. London, Sage Publications.

Yoon, M. (20II). More women in the Tanzanian legislature: Do numbers matter? Contemporary African Studies, 29 (I), pp. 83-98. 